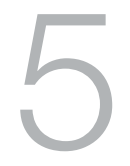

\title{
Declining fertility and the rising costs of children and the elderly in Japan and other selected Asian countries: An analysis based upon the NTA approach
}

Naohiro Ogawa, Rikiya Matsukura and Sang-Hyop Lee

Since the late 1960s, the growth of the world population has been steadily slowing down, primarily owing to an almost worldwide decline of fertility. Because of the reduction in world population growth rates in the second half of the 20th century, the outlook we have today is substantially different from the one we had a few decades ago. It is often mentioned by some demographers that while the 20th century was the century of 'population explosion', the 21 st is likely to become the century of 'population ageing' (Lutz et al. 2004).

At present, 60 per cent of the world population resides in Asia, and, of this percentage, almost half live in societies with below-replacement fertility. In particular, East Asia's fertility has been at the lowest level in the world in recent decades. In addition, mortality has been steadily improving over the past several decades, particularly in East and Southeast Asia. As a consequence of these demographic shifts, numerous Asian countries have been experiencing rapid population ageing, which is also being reflected in the increasing number of 
reports on a host of population ageing-related problems in the popular press in these countries. To address these ageing-related issues, a new analytical methodology called National Transfer Accounts (NTA) has been developed in the past 10 years (Lee and Mason 2011).

By drawing heavily upon the NTA system, Ogawa et al. (2015) have recently attempted to (1) examine, on the basis of a pool of time-series data, primarily from three low-fertility East Asian countries or areas (Japan, South Korea and Taiwan), the nexus between the direct public and private costs of children and the number of children that parents would raise during their reproductive span; and (2) investigate whether or not there exists a competing relationship between the young and the aged as recipients of private and public financial resources in the three East Asian countries. Along a similar line of interest, this chapter will expand the scope of analysis by adding a few more Asian countries (China, India, Thailand, the Philippines, and Vietnam) and by utilising more recent data for Japan and South Korea.

In the next section, we briefly highlight fertility, mortality and age compositional transformations that occurred over the last few decades in Japan and neighbouring East Asian countries (South Korea and Taiwan). In the subsequent section, some of the basic features of the system of NTA, which serves as the basic analytical framework of the present study, are succinctly presented. Following the NTA approach, we then analyse, for illustrative purposes, Japan's changing pattern of intergenerational transfers, both public and familial, over the past 25 years, especially focusing on the cost of children and the elderly. By combining computational results for Japan with those for seven other selected Asian countries (South Korea, Taiwan, China, India, Thailand, the Philippines, and Vietnam), we estimate the relationship between the cost of children and the fertility rate in those economies. In addition, we test, by employing a pooled dataset on the cost of children and the cost of the elderly, the applicability of the 'crowding out' hypothesis to these selected Asian countries. The final section summarises the major findings in the present study. 


\section{Declining fertility and population ageing in East Asia}

According to the most recent vital statistics available in the three East Asian countries, Taiwan's Total Fertility Rate (TFR) for 2013 was 1.07 children, the lowest among the three nations, followed by South Korea (1.24 children for 2014) and Japan (1.43 children for 2013). In hope of raising fertility, the three East Asian countries have been implementing a wide range of pronatalist policies and programs, but have had only limited success so far (Retherford and Ogawa 2009; Ogawa et al. 2015).

In Asia as a whole, Japan was the first country to experience a steep fertility decline. Furthermore, the magnitude of Japan's TFR decline, which occurred in post-war years, was one of the greatest among all industrialised nations. In fact, following a short baby boom period (1947-49), Japan's TFR declined by more than 50 per cent, from 4.54 to 2.04, during 1947-57. This dramatic reduction of fertility over a single decade is the first such experience in recorded history. Subsequent to this unprecedented fertility reduction in the 1950s, there were only minor fluctuations around the replacement level until the first oil crisis of 1973. Thereafter, the TFR started to fall again, hitting the 1.26 mark in 2005, which was an all-time low in Japan's modern history. It should be noted, however, that, after 2005, the Japanese TFR slowly recovered to 1.43 in 2013. Nonetheless, if fertility were to remain constant at the current level, each new generation would decline by 31 per cent.

East Asia's rapidly declining fertility has been attracting a substantial amount of attention, inside and outside the region in the past few decades. In contrast, however, a relatively limited amount of attention has been paid to the rapidity with which the mortality transition has been under way in the region over the past several decades. Japan's unprecedented mortality transition is a good illustration. Japan's life expectancy at birth in 1960 was 65.3 years for men and 70.2 years for women, and these two values were the lowest life expectancies among the OECD member countries at that time (Mason and Ogawa 2001). However, by the mid-1970s, Japanese life expectancy for both sexes combined became one of the highest among the OECD members. In 2013, Japan's male life expectancy at birth exceeded 80.2 years to become the fourth highest in the world, while its female 
life expectancy rose to 86.6 years, the highest in the world (National Institute of Population and Social Security Research 2015). As regards South Korea and Taiwan, the corresponding figures for females in 2013 were 85.1 and 82.8 years, respectively, and for males, 78.5 and 76.4 years (Statistics Korea n.d.; Department of Statistics, Ministry of the Interior, Republic of China (Taiwan) n.d.).

Because of such long-term transformations in both fertility and mortality, the age structures of the three East Asian economies have been shifting to a marked extent. In the case of Japan, the proportion of those aged 65 and over increased from 4.9 per cent in 1950 to 24.1 per cent in 2014, which indicates that Japan's population is currently the oldest in the world. In sharp contrast, the number of those aged below 15 has been declining for 33 consecutive years from 1982 to 2014, and Japan now has fewer children than at any time in the past 100 years (Statistics Bureau, Ministry of Internal Affairs and Communications, Japan 2015).

Moreover, although Japan's elderly population reached the 10 per cent level in 1984 and was the last to do so among the industrialised nations, Japan became the first industrialised country in which the aged comprise more than 20 per cent of the total population. The length of time required for the increase from 10 to 20 per cent was only 21 years. Compared with European countries such as Sweden and Norway, Japan is ageing approximately three times as fast. In addition, in the first half of the 21st century, both South Korea and Taiwan are projected to age faster than Japan despite the fact that the onset of the population ageing phenomena there came with a delay compared to Japan, with Taiwan catching up with Japan by 2054, and South Korea by 2059 (Ogawa et al. 2015)

\section{What can the National Transfer Accounts (NTA) do?}

With a view to analysing a host of socioeconomic and demographic problems caused by age structural transformation, the NTA Global Project, an international collaborative research project, was launched a few years after the turn of the century. At present, a total of 46 countries, including Australia, are participating. The project's 
principal objective is to develop the NTA, a methodological system for measuring economic flows across age groups, for each of the member countries.

Societies take different approaches to reallocating resources from surplus to deficit ages, and there are two possible methods. One is reliance on capital markets. Namely, individuals accumulate capital during their working lives and, when they are no longer productive, they support their consumption in old age by relying on capital income (interest, dividends, rental income, profits, etc.) and by liquidating their assets. The other method relies on transfers from those at surplus ages to those at deficit ages. Some of these transfers are mediated by the public sector, but many are private transfers, of which familial transfers are most important. The material needs of young children are fulfilled mostly by their parents, which is true everywhere in the world. In most Asian societies, familial transfers between adult children and the elderly are also very important. Some of these transfers are between households, but intra-household transfers seem to be of more importance, since family members in Asia tend to form multigeneration households that involve large intergenerational transfers.

The NTA provides a comprehensive framework for estimating consumption, production, and resource reallocations by age. The accounts are constructed so as to be consistent with and complementary to the National Income and Product Accounts (NIPA). The NTA are being constructed with sufficient historical depth to allow for analysis of key features of the transfer system, and can also be projected into the future and thus enable us to analyse the economic and policy implications of future demographic changes. Furthermore, sectoral disaggregation allows the analysis of public and private education and health care spending. It should be noted, however, that no gender differentiation is incorporated in the NTA system, except in an experimental way.

It is worth noting that a comprehensive volume containing numerous NTA country reports, and several chapters on the methodological basis of NTA and intercountry comparative analysis on selected topics, has already been published (Lee and Mason 2011). Furthermore, an NTA manual was published by the United Nations Population Division in 2013, intended for national experts and planners who are interested in constructing the NTA system for their country. 


\section{Calculating the private and public costs of children and the elderly}

\section{(a) Plausible theoretical links between the costs of children and the elderly}

According to the data gleaned in the three most recent rounds (2002, 2005, 2010, Kaneko et al. 2008 and NIPSSR 2011) of the Japanese National Fertility Survey conducted by the National Institute of Population and Social Security Research (NIPSSR), the high cost of children remains the most important reason for having fewer children among married women of reproductive age below 50. The survey respondents were asked to select as many possible replies as they wished from 13 precoded responses in order to explain why they did not intend to have their ideal number of children. The response category that attracted the largest number of responses was 'because rearing and educating children requires too much money'.

The foregoing result is consistent with what Becker's economic theory of fertility $(1960,1981)$ states. According to an essential idea of the Becker model, if parents spend a greater amount of resources on a child, they derive greater satisfaction because the child is of 'higher quality'. In Becker's fertility model, to increase the amount of satisfaction in the conditions where there is a higher private cost for having children, the parents opt for the substitution of quality for quantity of children, thus operating to decrease fertility. Consequently, Becker's model suggests that there exists a trade-off between the number of children in the family and the quality of children. It should also be stressed that, besides private costs of children, public spending on children may also play an important role in determining the quality and quantity of children parents have. For example, subsidising the quality of children reduces the private cost of acquiring high-quality children, thus leading to higher fertility.

More importantly, the trade-off between spending and the number of children is related to generational equity. Preston (1984) has raised the possibility that population ageing will lead to a decline in the welfare of children relative to the welfare of the elderly. In Japan, the cost of the elderly has been rising in parallel with the cost of children, partly owing to the maturity of the pension programs (Ogawa and 
Retherford 1997; Ogawa, Chawla and Matsukura 2010). In addition, as a consequence of the increased political power of the elderly induced by rapid population ageing, and due to the fact that the Japanese government's budgetary resources are severely constrained, it is highly conceivable that a 'crowding out' effect between the resources directed to the young and to the elderly might be occurring.

\section{(b) Age-specific profiles of per capita private and public consumption for children and the elderly}

Before proceeding any further, it should be pointed out that a fuller explanation of the NTA's basic concepts, containing the crucial computational assumptions, definitions of other key variables, and the theoretical consideration behind each key equation is available on the NTA website (www.ntaccounts.org). In this subsection, therefore, we confine ourselves to discussing primarily how the direct public and private costs of rearing children and supporting the elderly are computed in the NTA system.

In NTA, consumption, both private and public, is comprised of education, health, and other consumption (food, clothing, housing, durables, etc.). Moreover, because the young population, particularly at school ages, has little or no labour income, its consumption is virtually equal to the direct costs of raising children. In contrast, the direct living costs of the elderly need to be calculated as a difference between their consumption and labour income. In addition, it should be noted that, although the foregone income is an important part of the costs to be incurred in rearing children and taking care of elderly persons, it falls outside the scope of this paper.

The age-specific profile of the per capita private education cost is estimated by applying a regression equation to the micro-level data gathered in a nationally representative household income and expenditure survey. In the case of Japan, the equation is applied to the six rounds (1984, 1989, 1994, 1999, 2004 and 2009) of the National Survey of Family Income and Expenditure (NSFIE), carried out by the Statistics Bureau of Japan. Similarly, the age-specific profile of the per capita private health care cost is also estimated on the basis of the same survey data, using a similar regression equation. 
Furthermore, the age-specific profile of the per capita cost of private consumption, excluding private education and health, is estimated by a relatively simple a priori method, as shown below:

$$
\alpha(a)=1 \quad 0.6 \cdot D(4<a<20) \cdot \frac{20 \quad a}{16} \quad 0.6 \cdot D\left(\begin{array}{ll}
a & 4
\end{array}\right)
$$

Where $(a)=$ equivalence scale of age group $a$ and $D(z)$ is a dummy variable that takes the value of 1 when condition $z$ is met, but is otherwise zero. The computed equivalence scales at varying ages are as follows: 0.4 for the age group $0-4$, and 1.0 for the age group 20 and over, whereas the scale values for the age group 5-19 increase linearly with age.

Now, let us discuss the public costs of children and the elderly. The age-specific profile of the per capita public education cost is computed by utilising the published data on the government expenditure for each level of education and the number of pupils and students at each level of education in 1984, 1989, 1994, 1999, 2004 and 2009. The age-specific profile of the per capita health care expenditure is estimated on the basis of published government data concerning age-specific outpatient and inpatient costs per case and age-specific incidence of receiving such medical treatments. In the case of per capita expenditure on public consumption in general (e.g. government employees' salaries, road maintenance costs, national defence, etc.), we assume that every person consumes equally, and simply divide the total annual expenditure for each component of public consumption, except for education and health, by the total population.

Using these computed results for age-specific profiles of various components of consumption, we estimate the age-specific profile of per capita consumption for 1984, 1989, 1994, 1999, 2004 and 2009, private and public sectors combined. In Figure 1, we have plotted for illustrative purposes the estimated results of per capita total consumption only for three selected years (1984, 1994 and 2009). For comparative purposes, we have also plotted the corresponding age-specific profiles of per capita production (labour income) for the three selected years. (For a more detailed methodological explanation pertaining to the per capita production profiles, see Ogawa, Mason, Chawla and Matsukura 2010). It should be also noted that these estimated results are expressed in terms of year 2000 constant prices. 


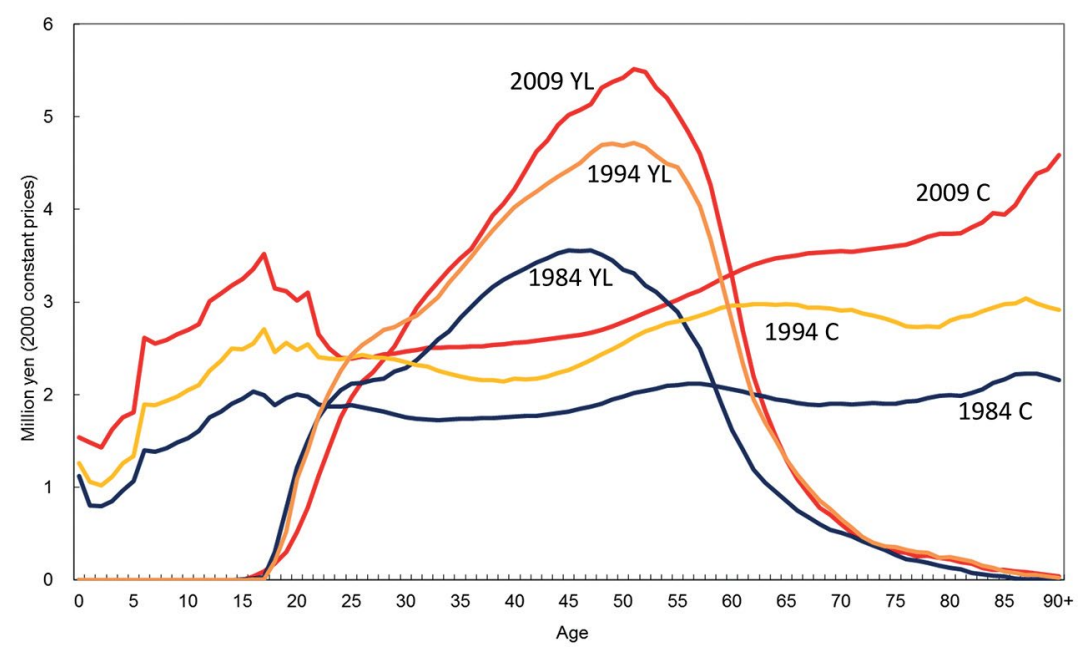

Figure 1. Age specific profiles for per capita consumption (C) and production (YL): Japan, 1984, 1994 and 2009

Source: Provided by author.

A few points of interest can be derived from this graphical exposition. First, by drawing upon information contained in Figure 1, we can calculate the size of income-consumption deficits by age in 1984, 1994 and 2009. Throughout the time under review, as shown in Figure 2, there are sizeable income-consumption deficits at both young and older lifecycle stages. Obviously, these lifecycle deficits (LCD) must be covered, with reallocations coming largely from the surplus of income generated at the lifecycle surplus stage during the current period or from assets accumulated during previous periods.

Second, it is also worth noting in Figure 1 that the age at which an average individual shifts from a net consumer to a net producer gradually increased from 23 years old in 1984 to 25 in 1994, and 29 in 2009. At the other end of the lifecycle, the age transition from a net producer to a net consumer was postponed only marginally from 58 years old in 1984 to 60 in 2009. The fact that the shift in the crossing age at the later stage of lifecycle was relatively small is attributable to the existence of the mandatory retirement age. (It should be noted, however, that as a result of a new legislation, the retirement age in Japan was gradually raised from 60 to 65 between 2006 and 2013.) 
Third, the age-profiles of per capita consumption were rising almost continuously over time. The 1984 and 1994 age-profiles show a mildly shaped double hump, being high at both young and older ages. The first peak corresponds to the high costs of the young, while the second peak is related to the high costs shouldered by household heads under multigenerational living arrangements. In addition, it is worth noting that the amount of per capita consumption rose distinctly among those aged 65 and over in 2009. This can be accounted for by the implementation of the Long-term Care Insurance (LTCI) scheme, starting from the year 2000. In-home care for the frail elderly, which had until then been informally provided by family members, thus became formalised as a part of the market economy. As a result, Japan's per capita consumption profiles have, over time, become more similar to those of the United States, Sweden and Costa Rica, among the NTA member countries (Tung 2011).

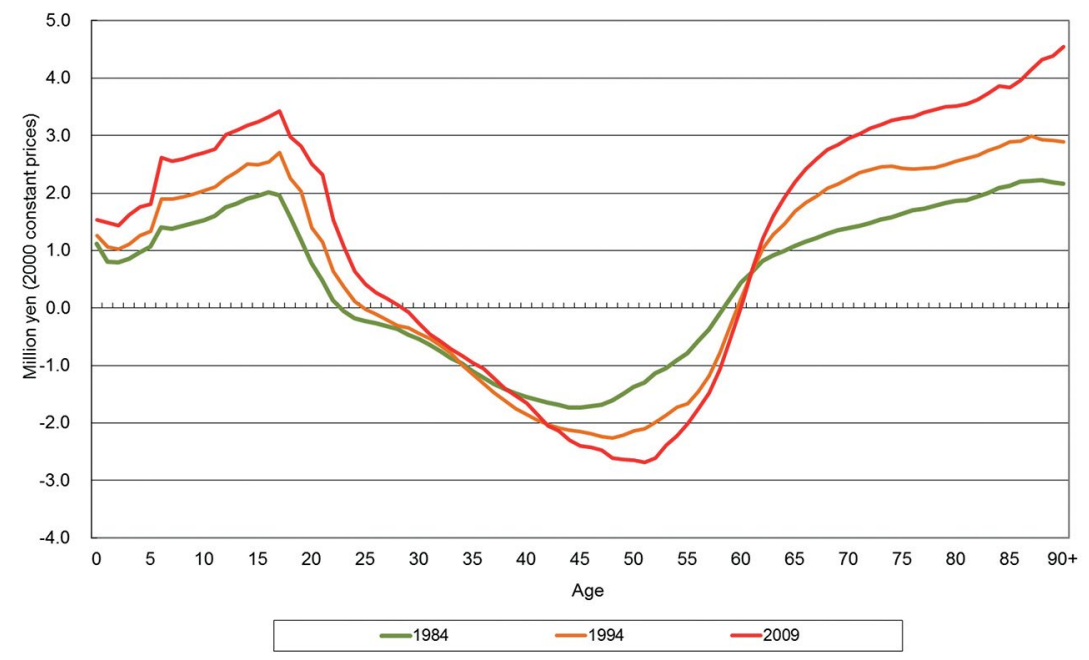

Figure 2. Lifecycle deficits: Japan. 1984, 1994 and 2009 Source: Provided by author.

\section{(c) Changing pattern of lifecycle deficits and total reallocations}

As is widely described in numerous publications pertaining to the system of NTA, the accounts measure intergenerational flows for a certain period of time (usually a calendar or fiscal year), and are governed by the following relationship: 


$$
y^{l}+y^{A}+\mathrm{t}_{g}^{+}+\mathrm{t}_{f}^{+}=C+S+\mathrm{t}_{g}+\mathrm{t}_{f}
$$

Where $y^{l}=$ labour income; $y^{A}=$ asset income; $\mathrm{t}_{g}^{+}=$public transfer inflows; $\mathrm{t}_{f}^{+}=$private transfer inflows; $C=$ consumption; $S=$ saving; $\mathrm{t}_{g}=$ public transfer outflows to the government; and $\mathrm{t}_{f}=$ private transfer outflows. Rearranging terms in Equation (2), the LCD, which is the difference between consumption and production, is matched by age reallocations consisting of reallocations through assets and net transfers, as expressed below:

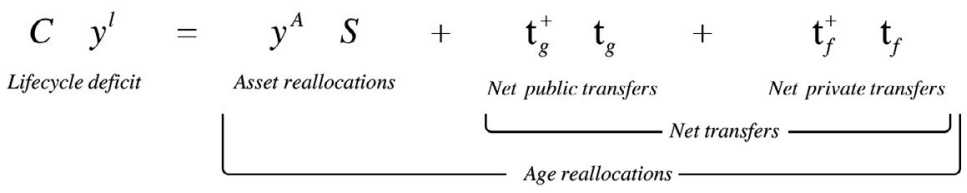

Furthermore, to gain further insight into Equation (3), we can express the mathematical relationship by using the relevant data for 2009 as illustrated in Figure 3. In this graphical exposition, the vertical scale represents age-specific per capita deficit, which corresponds to the difference between per capita consumption and per capita production at each age. It should be further noted that the graph indicating the age-specific aggregate-level deficit takes into consideration the number of persons at each age, thus showing a pattern substantially different from the one displayed in Figure 3.

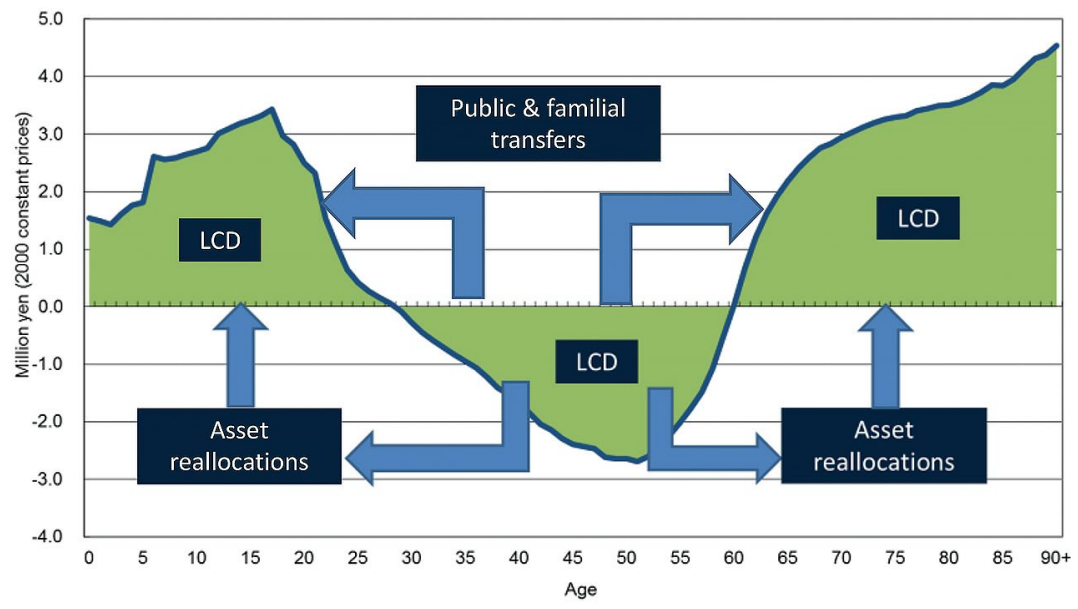

Figure 3. Total reallocations: Lifecycle deficits (LCD)

Source: Provided by author. 
At this point, caution should be exercised with regard to the following two remarks. First, both 'familial transfers' and 'private transfers' are used interchangeably in this paper; both of them refer to private transfers received by households from any source, of which the predominant share is, surely, familial transfers. Second, although net private transfers are comprised of bequests and inter vivo transfers, the computation of the bequest component has not been completed at the time of writing. For this reason, bequests are excluded from the computational results reported here.

By applying the time-series data for Japan to Figure 3, we have produced Figure 4, which shows how the pattern of three components of reallocation of the LCD changed in Japan over the past 25 years. The three components are reallocations through assets, public transfers, and private transfers, measured on an annual basis. Panels A, B and C illustrate annual reallocations of the LCD observed in 1984, 1994 and 2009.

A brief comparison of the three panels reveals the following three important results. First, there was a marked increase in the impact of the rapid growth of the elderly population upon transfers over time. The amount of net total transfers given to the elderly aged 65 and over increased by 3.5 times from 1984 to 2009 . Concretely, the amount of net public transfers to the elderly grew 5.4 times in real terms over this time period. It is also worth noting that the role of asset reallocations in financing the lifecycle deficits has become extremely important among the elderly population - the amount of asset-based reallocations increased by 12 times in real terms during 1984-2009. In the face of such phenomenal growth of the importance of assetbased allocations, however, the total amount of net public transfers dominated that of asset allocations in the elderly population in 2009.

Second, despite the shrinking of the young population, the total amount of net transfers to the population group aged 0-19 grew by 8 per cent during 1984-2009. It should also be added that the composition of the net transfers changed considerably over time. That is, during 1984-2009, the amount of net public transfers given to this age group rose by 37 per cent in real terms, while the corresponding figure for net familial transfers declined by 13 per cent. 
5. DECLINING FERTILITY AND THE RISING COSTS OF CHILDREN AND THE ELDERLY
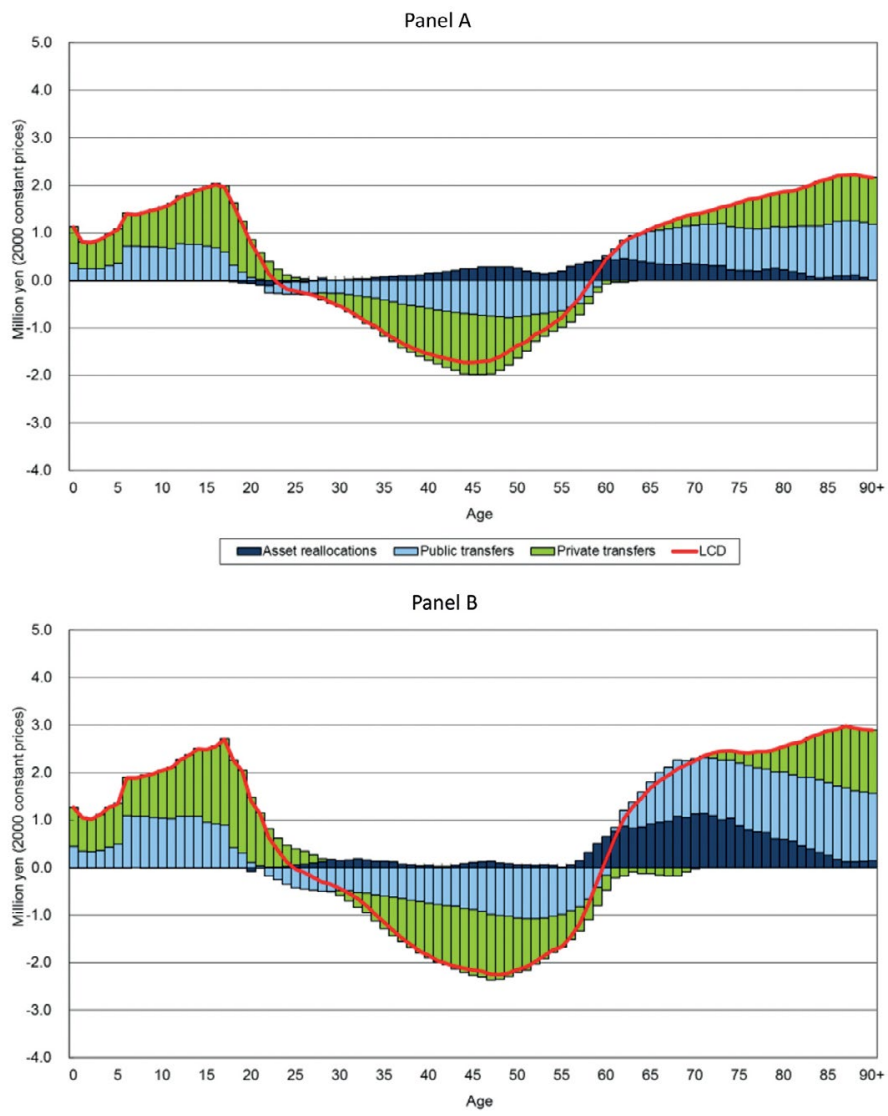

चsset reallocations $\square$ Public transfers $\square$ Private transfers —LCD

Panel C

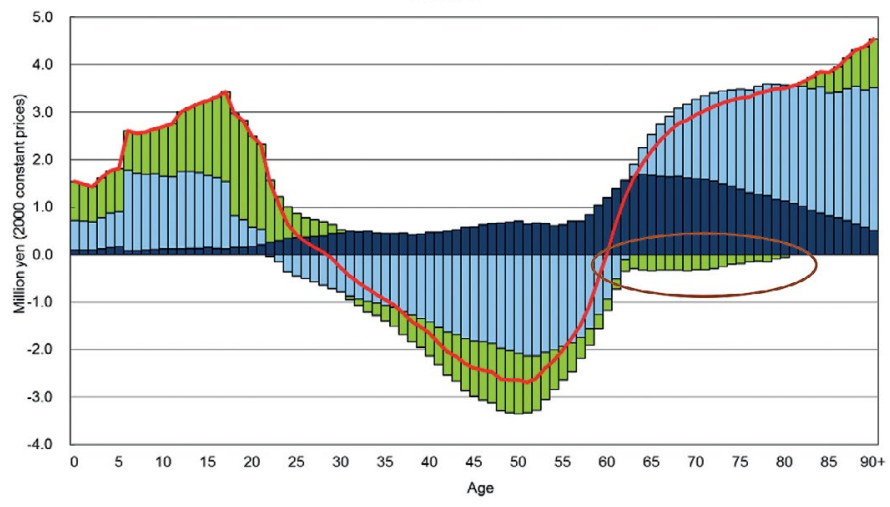

asset reallocations $\square$ Public transfers $\square$ Private transfers $-L C D$

Figure 4. Changing pattern of three components of per capita reallocation of lifecycle deficit: Japan. (a) 1984, (b) 1994, and (c) 2004.

Source: Provided by author. 
Third and more important, the net familial transfers are negative among relatively young elderly persons. As indicated by a circle in Panel C of Figure 4, this phenomenon is particularly pronounced in 2009 among the elderly in their 60s and 70s. This implies that the amount of financial assistance that the relatively young elderly persons provided to their adult children and/or grandchildren exceeded the monetary assistance from the latter to the former. It is also worth noting that the amount of these negative net familial transfers from the relatively young elderly to other age groups rose during the prolonged deflationary period beginning from the mid-1990s. Up until the early 2010s, the unemployment rate remained at a high level and labour income hardly grew at all in both nominal and real terms.

\section{Rising per capita costs of children and the elderly in selected Asian countries}

To facilitate our analysis in this section, we define the following two new variables: 'the child $\mathrm{LCD}^{\prime}$ and 'the elderly $\mathrm{LCD}^{\prime}$. The former represents the per capita direct cost of raising children up to their self-sufficient ages, i.e. the age at which the age-specific LCD shifts from positive to negative, based upon the system of NTA. The latter represents the per capita direct cost of the elderly from the age at which they cease to be self-sufficient up to the age of their death. The per capita direct cost of the elderly corresponds to the sum of the age-specific LCD, computed as consumption minus production.

\section{(a) Spending per child and the number of children in Japan and other selected Asian countries}

As previously discussed, one of the most crucial concepts in the economics of fertility is the trade-off between the spending per child and the number of children, and this idea is fully embedded in Becker's model of fertility decision-making (Becker 1960, 1981). Becker's theory states that higher income leads to an increase in the demand for higher-quality children and a more modest increase in the demand for the number of children (quantity). But because higherquality children are costly, this leads couples to substitute away from quantity. In other words, the basic trade-off has to do with private costs 
of children, i.e. costs borne by the fertility decision-makers (parents). Moreover, public spending on children may play an important role as well. For instance, with the provision of government subsidies for improving the quality of children, the private cost of acquiring highquality children is likely to be reduced, which may result in raising fertility.

As mentioned in the previous section, the child LCD is the consumption of children (both public and private) minus the value of labour by children, i.e. the cost that children themselves cover. The child LCD is calculated for single years of age and can be used to construct a synthetic cohort measure of the cost of children. It represents the direct cost of children, assuming that they were raised from birth to adulthood consuming and producing at the same age-specific rates that prevailed in the year in question.

We normalise the child LCD by dividing it by the mean labour income of prime-age adults aged 30-49. This facilitates comparison across countries and also indirectly controls for the effects of income on child spending. In order to allow for mortality risks in childhood, we have also adjusted the normalised child LCD, by using appropriate life table values. Thus, the computed values can be interpreted as the years of prime-age adult labour devoted to rearing a child from birth to economic independence, or to the child's death, should that occur during childhood.

Using the computed results of the child LCD per person below a selfsufficient age and the mean per capita labour income of adults aged 30-49 for Japan, we have calculated the normalised per capita child LCD adjusted for survivorship up from birth to the self-supporting age in 1984, 1989, 1994, 1999, 2004 and 2009. The calculated values increased monotonically over time, namely, 9.6 years of labour income in 1984, 10.3 years in 1989, 10.9 years in 1994, 11.9 years in 1999, 13.0 years in 2004, and 14.1 years in 2009. In addition, we have carried out the same computation for Taiwan (1981-2005) and South Korea (1996-2010). In the case of Taiwan, the normalised per capita child LCD adjusted for survivorship increased almost continuously from 7.7 years in 1981 to 16.6 years in 2005. In the case of South Korea, the corresponding value rose linearly from 9.0 years in 1996 to 14.1 years in 2010. Besides these three East Asian countries, we have 
included in the analysis the normalised per capita child LCD adjusted for survivorship for the following five Asian countries: China in 2002 (6.5 years of the mean labour income), India in 2004 (9.0 years), Thailand over the period 1981-2004 (from 8.0 years to 10.4 years), the Philippines in 1999 ( 7.8 years), and Vietnam in 2008 (8.5 years).

In order to quantitatively examine the trade-off between spending on children and the number of children, we have pooled the results on the child LCD derived from the eight countries, and have linked them to the time-series data on TFR for each country under investigation. In the case of Japan, TFR declined considerably from 1.81 in 1984 to 1.37 in 2009. Taiwan's TFR declined substantially from 2.46 to 1.12 from 1981 to 2005, while South Korea's TFR fell from 1.60 to 1.22 during the period 1996-2010. In the case of Thailand, the TFR declined from 3.69 in 1981 to 1.66 in 2004 . TFRs for the remaining four countries were as follows: 1.82 for China, 2.85 for India, 3.56 for the Philippines, and 2.08 for Vietnam.

In Figure 5, a total of 51 data points of the normalised per capita child LCD for the eight Asian economies for various years are plotted, coupled with the TFR for the corresponding years. As displayed in this graph, we have fitted the data by regressing the natural logarithm of the normalised per capita child LCD onto the natural logarithm of the TFR and, hence, the coefficient is the elasticity of the qualityquantity trade-off.

As is well-known, a coefficient of -1 implies that a 1 percentage point decrease in the number of children is accompanied by a 1 percentage point increase in the cost of children and, hence, the total change in spending by adults on childrearing remains constant. As presented in Figure 5, the estimated elasticity for the eight Asian countries combined is -0.698 , implying that a 1 percentage point decrease in the TFR leads to a less than 1 percentage point increase in the total cost of childrearing per adult. 


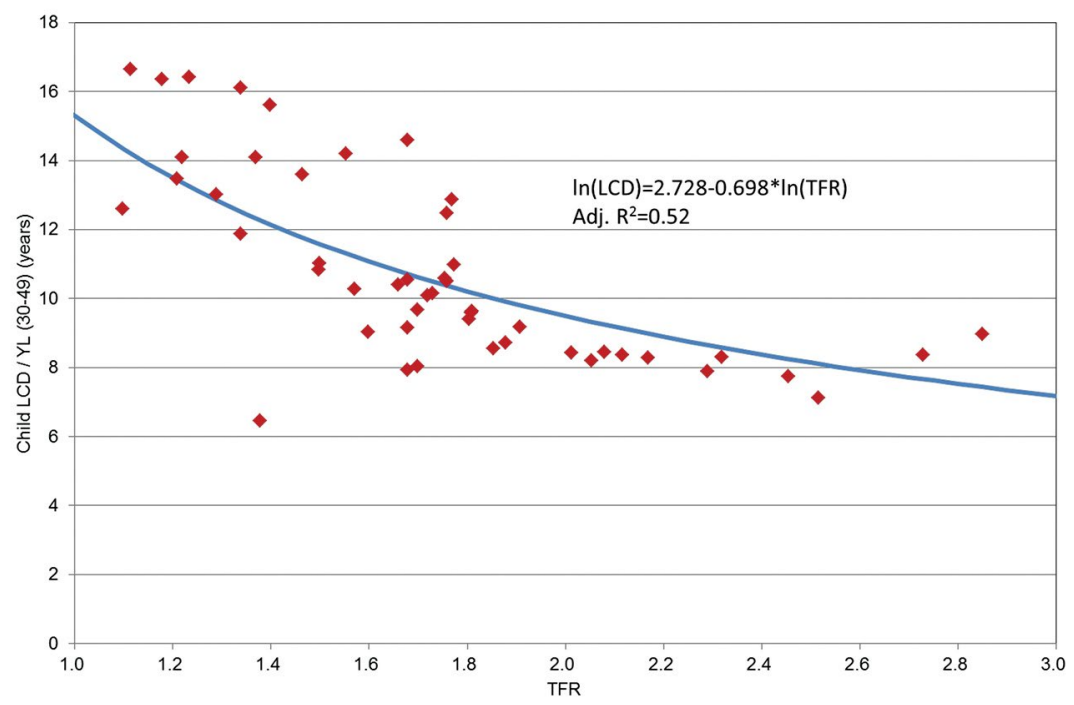

Figure 5. TFR versus normalised per capita LCD for children: Selected Asian countries

Source: Provided by author.

This result has changed dramatically once we have undertaken a regression analysis, as displayed in Figure 6, by focusing on the relationship between the human capital component (education and health costs) of per capita child LCD and the TFR. It should be noted that, except for the fact that we have used the human capital component of the per capita child LCD in place of the per capita child LCD as a whole, all the data points plotted in Figure 6 have been constructed in the same manner as in Figure 5. The regression result indicates that the computed elasticity $(-1.512)$ is much larger than the one shown in Figure 5 for the total cost of children. This elasticity is also much larger than the cross-sectional elasticity reported by Lee and Mason (2010). In addition, the goodness of fit, as measured by adjusted $\mathrm{R}^{2}$, is better in the case of the computed result shown in Figure 6 than in Figure 5. Hence, the health and education components of per capita child LCD are more closely linked to fertility change than the other components of child LCD. This finding is consistent with the widely held view that human capital factors have been playing an important role in the relationship between economic growth and fertility change in Asian countries, particularly in East Asia (Ogawa, Retherford and Matsukura 2009; McDonald 2009). 


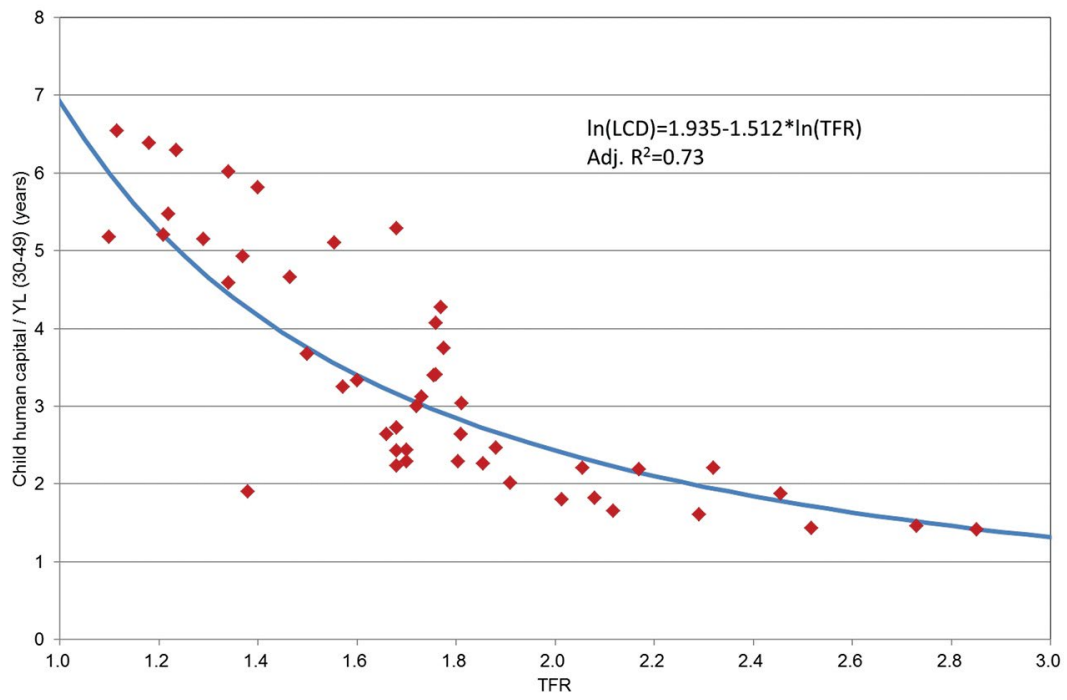

Figure 6. TFR versus normalised per capita human capital spending for children: Selected Asian countries

Source: Provided by author.

For the purpose of shedding more light on the nexus between human capital factors and fertility, we have conducted the following two additional regressions for the eight Asian countries. In one of them, we have fitted the data by regressing the natural logarithm of normalised per capita public human capital spending onto the natural logarithm of the TFR. In the other regression, the natural logarithm of normalised per capita private human capital spending has been regressed on the natural logarithm of the TFR. The results of these regressions, not detailed here, indicate that both the public and private components of human capital spending have fairly comparable association with fertility, i.e. the elasticity of -1.302 for public human capital spending and the elasticity of -1.618 for private human capital spending.

These computational results appear to be inconsistent with those obtained in the work recently undertaken by Lee and Mason. In their recent analysis of NTA data covering 19 countries (including not only Asian, but also European and Latin American countries), Lee and Mason (2010) have found that the quantity-quality trade-off is very strong for public spending (particularly on education) but not for private human capital spending. As displayed in Table 1, however, 
private human capital spending (particularly education) tends to be very large, and even exceeds public human capital spending in the Asian economies, particularly in such East and Southeast Asian countries as South Korea, Taiwan, China, and Vietnam. More importantly, it should be noted that primarily because East and Southeast Asia are 'success-oriented' societies, parents in this region are prone to spend a vast amount of financial resources on their children's education (McDonald 2008).

Table 1. Proportion of private spending in per capita educational costs for children and youths aged 0-24: Selected economies

\begin{tabular}{|l|c|c|}
\hline Country & Year & Percentage \\
\hline Sweden & 2003 & 3.1 \\
\hline France & 2001 & 5.0 \\
\hline Austria & 2000 & 5.8 \\
\hline Slovenia & 2004 & 8.7 \\
\hline Hungary & 2005 & 11.1 \\
\hline US & 2003 & 17.0 \\
\hline Costa Rica & 2004 & 22.3 \\
\hline Japan & 2009 & 26.0 \\
\hline India & 2004 & 38.9 \\
\hline Chile & 1997 & 39.4 \\
\hline Indonesia & 2004 & 39.6 \\
\hline Uruguay & 1994 & 46.4 \\
\hline Philippines & 1999 & 48.2 \\
\hline South Korea & 2005 & 51.6 \\
\hline Taiwan & 2005 & 69.4 \\
\hline China & 2002 & 71.2 \\
\hline Vietnam & 2008 & 75.6 \\
\hline
\end{tabular}

Source: Author's calculations.

The regression results presented thus far appear to conform to the view that there is a distinctive trade-off between the number of children and the combined (familial and public) spending per child in East Asia. Caution should be exercised, however, in interpreting these fitted results. It should be noted that all the regressions for the Asian countries are based upon a mix of cross-section and timeseries data heavily dominated by Taiwan. Given such limitations, 
the fixes that are usually employed to deal with well-known statistical problems that limit the value of aggregate regression estimates are not practical in this case. Moreover, these regression results do not represent causal relationships. That is, the variable on the right-hand of the regressions is not necessarily an explanatory variable, while the variable on the left-hand of the regressions is not necessarily a dependent variable. Hence, the regressions estimated here should be treated only as descriptive device, thus making causal interpretation impossible.

\section{(b) The nexus between the per capita child LCD and the per capita elderly LCD}

In recent years, the cost of the elderly has also been rising in ageing Asia, particularly in East Asia (Takegawa 2005). A question therefore arises: is there a 'crowding out' effect between the resources going to the young and those allotted to the elderly? To shed some light on this question, we have calculated (1) how many years of the mean labour income of prime-age adults aged 30-49 is needed to finance the per capita LCD for a child, and (2) how many years of prime-age mean labour income is required to finance the per capita LCD for an elderly person. The data for the computation have been prepared for the same eight Asian countries in the same manner as in our foregoing analysis pertaining to the cost of children and fertility.

The computed results are plotted in Figure 7. The pattern emerging from this graph seems to roughly indicate that both the cost of a child and the cost of an elderly person tend to grow in the same direction, thus suggesting that there is no distinctive 'crowding out' effect in these eight Asian economies. (The simple correlation coefficient between the two variables shown in this graph amounts to 0.791.) These results seem to suggest that in these Asian countries, workingage adults are sandwiched by their elderly parents and their children, heavily relying on assets to meet their own material needs as well as their familial and social obligations to other generations. 


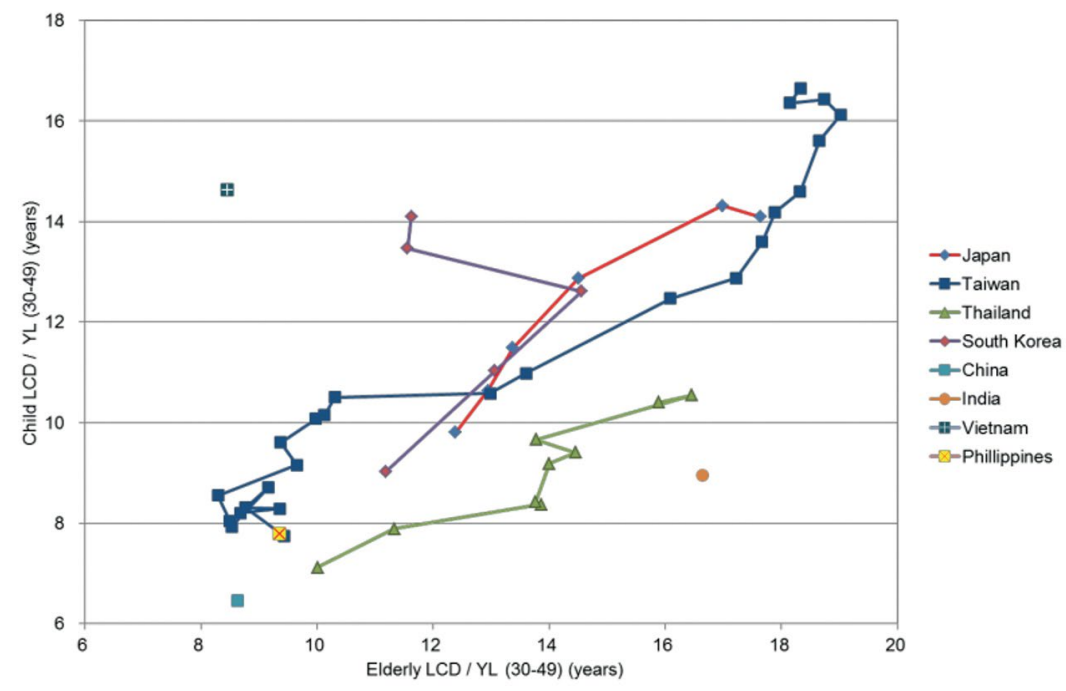

Figure 7. Relationship between the cost of children and the cost of the elderly: Selected Asian countries

Source: Provided by author.

For comparative purposes, we have calculated the cost of a child and the cost of an elderly person for NTA member countries in other regions. Although relevant graphs are omitted, the following two observations can be safely made. First, in both Latin America and Africa, we found virtually the same pattern as the one prevailing in the selected Asian countries. Second, European countries show a totally different pattern from these developing countries, and the cross-sectional data gleaned from the European countries involved in the NTA project indicates that there is no significant relationship between the costs of the two age groups.

\section{Concluding remarks}

In the present study, we have examined the relationship between the cost of raising children up to self-supporting ages and the number of children parents have, by drawing heavily upon the computed results for the eight selected Asian countries. The results suggest that the two variables in question have a negative association in the case of these eight Asian economies, and that the calculated elasticity is -0.698 . 
More importantly, as regards the per capita child human capital costs and the TFR, the calculated elasticity amounts to -1.512 , which suggests that, in the eight Asian countries under examination, the health and education component of the per capita child LCD is more closely linked to changes in fertility than the other components of the per capita child LCD.

So, what can the Asian economies with below-replacement fertility do to restore their fertility levels in the years to come? The fact that higher-quality children are costly leads couples to substitute away from quantity. This basic trade-off relationship between the quality and quantity of children plays a crucial role in determining the private cost of children defrayed by parents. Moreover, public spending on children also plays a vital role in this respect. By subsidising the quality of children through public resources, for example, the cost of acquiring high-quality children is reduced, and consequently higher fertility is encouraged.

Apart from the provision of government subsidies for pronatalist purposes, the child LCD can also be reduced by lowering the selfsupporting ages. One of the possible policy measures for this purpose is creating more stable full-time job opportunities for young workers. In the case of a shrinking population such as that of Japan, hourly labour productivity can be raised through better vocational and onthe-job training. In addition, greater women's labour force participation is another option, but methods for ameliorating the potential impact of female paid employment on fertility need to be carefully considered before implementing this policy option.

The trade-off between the cost of children and the number of children is important not only in terms of formulating effective fertility policies but also from the standpoint of generational equity. As hypothesised by Preston (1984), population ageing induced by reduced fertility and extended longevity should lead to a decline in the welfare of children relative to the elderly. However, contrary to Preston's hypothesis, one of the conclusions derived from our study is that the 'crowding out' phenomenon between children and the elderly competing for limited public and private resources could not be observed in the eight selected Asian countries in the past two decades or so. 


\section{Acknowledgements}

This work has been supported by JSPS KAKENHI Grant Number $15 \mathrm{H} 05692$.

\section{References}

Becker Gary (1960). An economic analysis of fertility. In Demographic and Economic Change in Developed Countries, National Bureau of Economic Research Special Conference Series 11, Columbia: Columbia University Press, pp. 209-231.

Becker Gary (1981). A Treatise on the Family. Cambridge, Massachusetts and London, England: Harvard University Press.

Department of Statistics, Ministry of the Interior, Republic of China (Taiwan) (n.d). Statistical Yearbook of Interior. eng.stat.gov.tw/ ct.asp? $x$ Item $=6503 \&$ CtNode $=2202 \& m p=5$.

Kaneko Ryuichi, Sasai Tsukasa, Kamano Saori, Iwasawa Miho, Mita Fusami and Moriizumi Rie (2008). Marriage Process and Fertility of Japanese Married Couples, The Japanese Journal of Population, 6(1): 24-50.

Lee Ronald and Mason Andrew (2010). 'Fertility, human capital, and economic growth over the demographic transition'. European Journal of Population, 26(2): 159-182.

Lee Ronald and Mason Andrew (Eds) (2011). Population Aging and the Generational Economy: A Global Perspective. Cheltenham, Northampton, Ottawa: Edward Elgar and International Development Research Centre.

Lutz Wolfgang, Sanderson Warren and Scherbov Sergei (2004). The End of World Population Growth in the 21st Century: New Challenges for Human Capital Formation and Sustainable Development. London and Sterling, VA: Earthscan. 
Mason Andrew and Ogawa Naohiro (2001). Population, labor force, saving and Japan's future. In Magnus Blomström, Byron Gangnes, and Sumner La Croix (Eds) Japan's New Economy: Continuity and Change in the Twenty-First Century. Oxford: Oxford University Press, pp. 48-74.

McDonald Peter (2008). Low fertility as a macro-sociological issue: an application to East Asia. Paper presented at the International Conference on Low Fertility and Reproductive Health in East and Southeast Asia, organised by Nihon University Population Research Institute, in cooperation with WHO, UNFPA, IUSSP, and The Mainichi Daily Newspapers Tokyo, Japan, 12-14 November.

McDonald Peter (2009). Explanations of low fertility in East Asia: a comparative perspective. In Gavin Jones, Paulin Tay Straughan, and Angelique Chan (Eds) Ultra-low Fertility in Pacific Asia: Trends, Causes and Policy Issues. Abingdon: Routledge, pp. 23-39.

National Institute of Population and Social Security Research (NIPSSR) (2011). Marriage Process and Fertility of Japanese Couples. Tokyo: NIPSSR.

National Institute of Population and Social Security Research (NIPSSR) (2015). Latest Demographic Statistics, Population Research Series No. 333. Tokyo: NIPSSR.

Ogawa Naohiro, Chawa Amonthep and Matuskura Rikiya (2010). Changing intergenerational transfers in aging Japan. In Karen Eggleston and Shripad Tuljapurkar (Eds) Aging Asia: The Economic and Social Implications of Rapid Demographic Change in China, Japan, and South Korea. Baltimore: The Brookings Institution, pp. 43-62.

Ogawa Naohiro, Mason Andrew, Chawla Amonthep and Matsukura Rikiya (2010). Japan's unprecedented aging and changing intergenerational transfers. In Takatoshi Ito and Andrew $\mathrm{K}$ Rose (Eds) The Economic Consequences of Demographic Change in East Asia, NBER-EASE Vol. 19. Chicago and London: University of Chicago Press, pp. 131-160.

Ogawa Naohiro, Mason Andrew, Chawla Amonthep, Matsukura Rikiya and Tung An-Chi (2009). Declining fertility and the rising cost of children: What can NTA say about low fertility in Japan and other Asian countries? Asian Population Studies, 5(3): 289-307. 
Ogawa Naohiro, Mason Andrew, Lee Sang-Hyop, Tung An-Chi and Matsukura Rikiya (2015). Very low fertility and the high costs of children and the elderly in East Asia. In Naohiro Ogawa and Iqbal Shah (Eds) Low Fertility and Reproductive Health in East Asia. New York and London: Springer, International Studies in Population, pp. $31-58$.

Ogawa Naohiro and Retherford Robert (1997). Shifting costs of caring for the elderly back to families in Japan. Population and Development Review, 23(1): 59-94.

Ogawa Naohiro, Retherford Robert and Matsukura Rikiya (2009). Japan's declining fertility and policy responses. In Gavin Jones, Paulin Tay Straughan, and Angelique Chan (Eds) Ultra-low Fertility in Pacific Asia: Trends, Causes and Policy Issues. Abingdon: Routledge, pp. 40-72.

Preston Samuel H (1984). Children and the elderly: Divergent paths for America's dependents. Demography, 21(4): 435-458.

Retherford Robert D and Ogawa Naohiro (2009). Guest editors' introduction. Asian Population Studies, 5(3): 211-213.

Statistics Bureau, Ministry of Internal Affairs and Communications, Japan (2015). Population Estimates. Tokyo: Statistics Bureau, Ministry of Internal Affairs and Communications, Japan.

Statistics Korea (n.d). Vital Statistics (number and rate), data downloaded from Korean Statistical Information Service, kosis.kr/ eng/statisticsList/statisticsList/statisticsList_01List.jsp? vwcd $=\mathrm{MT}_{\text {_ }}$ ETITLE\&parentId $=\mathrm{A}$.

Takegawa Shogo (2005). Japan's welfare-state regime: welfare politics, provider and regulator. Development and Society, 34(2): 169-190.

Tung An-Chi (2011). Consumption over the lifecycle: an international comparison. In Ronald Lee and Andrew Mason (Eds) Population Aging and the Generational Economy: A Global Perspective. Cheltenham, Northampton, Ottawa: Edward Elgar and International Development Research Centre, pp. 136-160. 
This text is taken from Population Ageing and Australia's Future, edited by Hal Kendig, Peter McDonald and John Piggott, published 2016 by ANU Press, The Australian National University, Canberra, Australia. 